\title{
Perspective on Sustainable Energy Technologies in Asia and Pacific States
}

\author{
Received April 5, 2010
}

During the last 20 years, there has been a growing realization that sustainable development must receive a higher priority in the years ahead. There is a particular need for scientists and engineers with expertise in sustainability who can develop innovative solutions to the problem of dwindling natural resources. Pressing issues of global concern in all dimensions of sustainable development are economical, ecological, and social. Poverty eradication is the most pressing issue of development policy, as captured in the Millennium Development Goals. Climate change is undoubtedly one of the most serious concerns of our time. Scientists and engineers strive to highlight the contribution that renewable energies can bring to reduce our energy-related $\mathrm{CO}_{2}$ emissions. The effects of climate change already demand reaction and adaptation. At the same time, efforts to mitigate climate change must be reinforced. The rapid expansion of renewable energies is arguably one of the most effective options to mitigate climate change and adapt to its effects. Energy security has risen to the top of the political agenda again since 2005 . Its meaning, though, has expanded from the mere reliability of supply to include a variety of issues. The term today covers various aspects, from security of infrastructure, investment regimes, long-term resource availability, and revenues for suppliers to security from risks of price variations for consumers, access to energy, and others. Renewable energy is considered generally as a sustainable energy. Nonetheless, environmental and social issues of renewable energy technologies do arise with increasing significance in recent years.

The Asia Pacific Congress on Sustainable Energy and Environmental Technologies (APCSEET) offered a good academic platform to show the latest research achievements in sustainable energy and environmental technologies in Asia and Pacific nations. The first APCSEET was held in Singapore in 1996. It was followed by conferences in Australia in 1998, Hong Kong in 2000, Japan in 2003, New Zealand in 2005, and Thailand in 2007. Through active preparation, the seventh APCSEET opened on October 15, 2009. At this special moment, it is really a great honor and pleasure for me to have hosted the seventh APCSEET in Qingdao. On behalf of the China University of Petroleum and Research Center of Eco-Environmental Sciences, China Academy of Sciences, I congratulate the APCSEET conference and extend my warm gratitude to all of the guests and experts working on energy and environmental technologies from Asia and Pacific nations!

APCSEET was conceived as an international biennial forum to foster communication between scientists and engineers involved in the invention, design, and development of sustainable technologies and the planners, policy makers, managers, and businesses involved in implementation. APCSEET was and still is intended as a showcase for stateof-the-art research through cutting-edge science, technology, and engineering, with particular attention and reference to issues from the Asia-Pacific region. In the 7th APCSEET proceedings, 340 abstracts, which includes 8 invited 60 plenary, 16 keynote, 150 oral, and 170 poster presentations, were collected. The broad scope of the technical program and plenary and keynote addresses by invited speakers on the integration of technical know-how with long-term planning for sustainability constitute a program designed to encourage and stimulate fresh perspectives on the challenges, opportunities, and solutions to energy and environmental sustainability. More than 320 scientists working in the energy and environmental fields have come to Qingdao to attend the congress entitled "Sustainable energy and environmental technologies in 21 st century", in which they exchanged the development of new technologies and showed the latest achievements in energy and environmental technologies. It is actually an important research fair of energy and environmental technologies in 2009, in which more than 200 papers cover the technologies on new and renewable energies. In this special issue, 11 papers on sustainable energy technologies were collected, which all are representative researches in this area.

In recent years, a number of governments enacted new policies and many countries set ambitious targets. Asia and Pacific developing countries, particularly China and India, are increasingly playing major roles in both the manufacture and installation of renewable energy, such as biofuels, which are a much needed sustainable energy source. The changing competitiveness and new policies for bioenergy in the transport, heat, and electricity sector have created a whole range of opportunities for bioenergy, including global bioenergy trade. The rapid growth in a multitude of technologies for production and use is fueling concerns about sustainability. Such efforts were tentatively shown in this issue.

Expert views on long-term energy development are becoming increasingly demanding and are relevant far beyond energy policy. The way renewable energies are presented in future scenarios and especially in the most widely recognized ones has important political implications. Underestimated renewable energy scenarios may misguide policy makers about how high the potential really is of renewable energies. It was also shown in this issue.

Our critical concerns are to achieve sustainable and environmentally friendly development. I believe that the special issue on APCSEET 2009 might be a new breakpoint in the creative study in sustainable energy technologies. There seems little doubt that the design, conversion, production, and application of sustainable and renewable energies will 
continue to grow in importance. It is hoped that readers will find that the range of sustainable energy covered in this special issue of Energy \& Fuels is of interest to them and that the information provided acts as a useful stimulus to new research. The seventh APCSEET was a complete success!

$$
\text { Zi-Feng Yan* }
$$

State Key Laboratory for Heavy Oil Processing, China National Petroleum Corporation (CNPC) Key Laboratory of Catalysis, China University of Petroleum, Qingdao 266555, China
Zheng-Ping Hao

Department of Environmental Nano-materials, Research Center for Eco-Environmental Sciences, Chinese Academy of Sciences, Beijing 100085, China

$\operatorname{Max} G . Q . L u$

Australian Research Council (ARC) Centre of Excellence for Functional Nanomaterials, School of Engineering and Australian Institute for Bioengineering and Nanotechnology, The University of Queensland, Brisbane 4072, Australia 